\title{
Pembelajaran Bahasa Arab Bagi Anak Berkebutuhan Khusus di Kelas III SD Qaryah Thayyibah Purwokerto
}

\author{
${ }^{1 *}$ Devi Ambarwati, ${ }^{2}$ Abdal Chaqil Harimi \\ 12IAIN Purwokerto \\ 1*ambarqurtuby2409@gmail.com \\ 2 abdal@iainpurwokerto.ac.id
}

$$
\begin{aligned}
& \text { الخلاصة: استراتيجية التعلم هي خطة وقواعد وخطوات ووسائل يتم ممارستها عملياً في عملية التدريس والتعلم في الفصل من أجل }
\end{aligned}
$$

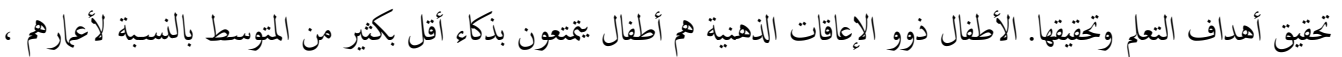

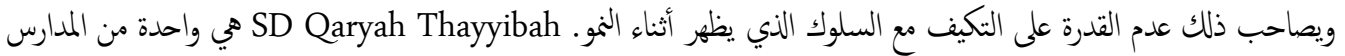

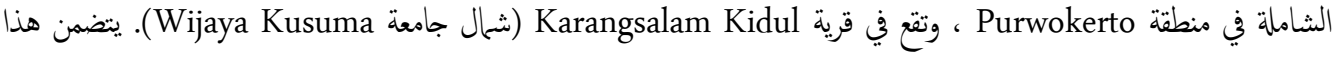

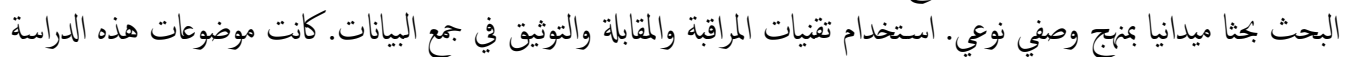

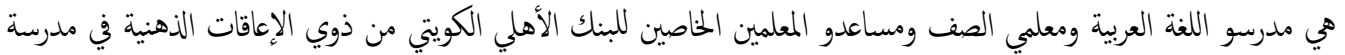

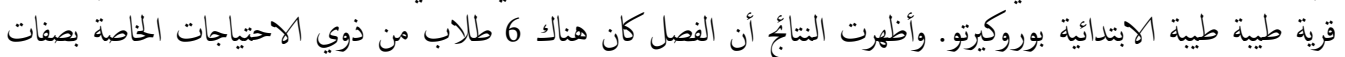



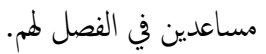

$$
\begin{aligned}
& \text { الكلمات المفتاحية: استراتيجيات النعلم ، الأطفال ذوي الاحتياجات الخاصة ، اللغة العربية }
\end{aligned}
$$

\begin{abstract}
Learning strategy is a plan, rules, steps, and means that will be played in the teaching and learning process in the classroom to achieve and realize learning objectives. Children with intellectual disabilities have intelligence that is significantly below the average for their age and accompanied by an inability to adapt behaviour that appears during development. SD Qaryah Thayyibah is one of the inclusive schools in the Purwokerto area, located in the village of Karangsalam Kidul (north of Wijaya Kusuma University). This research includes field research with a qualitative descriptive approach. They were using observation, interview and documentation techniques in data collection. The subjects of this study were Arabic language teachers, homeroom teachers and special assistant teachers for ABK with intellectual disabilities at Qaryah Thayyibah Elementary School, Purwokerto. The results showed that in the class, there were six students with special needs with different characteristics. Arabic for Children with Special Needs in the class is only an introduction. The obstacle experienced is the lack of class assistant teachers for them.
\end{abstract}

Kata kunci: Keywords: Learning strategies, Children with Special Needs, Arabic

\section{PENDAHULUAN}

Anak Berkebutuhan Khusus (ABK) adalah anak-anak yang memiliki keunikan tersendiri yang berbeda dari anak-anak pada umumnya. Menurut Howard, anak berkebutuhan khusus adalah anak-anak dengan karakteristik khusus yang berbeda dengan anak pada umumnya tanpa selalu menunjukkan pada ketidakmampuan 
mental atau fisik. ${ }^{1}$ Pembelajaran untuk ABK (student with special needs) membutuhkan suatu strategi tersendiri sesuai dengan kebutuhan masing-masing. Dalam penyusunan program pembelajaran untuk setiap bidang studi hendaknya guru kelas sudah meliliki data pribadi setiap peserta didiknya. Data pribadi yakni berkaitan dengan karakteristik spesifik, kemampuan dan kelemahannya, kompetensi yang dimiliki dan perkembangannya.

Karakteristik spesifik student with special needs pada umumnya berkaitan dengan tingkat perkembangan fungsioanal. Karakteristik spesifik tersebut meliputi tingkat perkembangamn sensori motor, kognitif, kemampuan berbahasa, ketrampilan diri, konsep diri, kemampuan berinteraksi sosial serta kreatifitasnya. Untuk mengatahui secara jelas tentang karakteristik dari setiap siswa, seorang guru terlebih dahulu melakukan skrinning atau assesment agar mengatahui secara jelas mengenai kompetensi diri peserta didik yang bersangkutan. Tujuannya agar saat proses pembelajaran sudah dipikirkan mengenai strategi pembelajaran yang dianggap cocok. Assesmen di sini adalah prosess kegiatan untuk mengatahui kemampuan dan kelemahan setiap peserta didik dalam segi perkembangan kognitif dan perkembangan sosial melalui pengamatan yang intensif.

Secara umum strategi mempunyai pengertian suatu garis-garis besar haluan untuk bertindak dalam usaha mencapai sasaran yang telah ditentukan. ${ }^{2}$ Sedangkan pembelajaran merupakan aktifitas untuk mentransformasikan bahan pelajaran kepada subjek belajar, dalam konteks ini guru berperan sebagai penjabar, penerjemah bahan tersebut supaya dimiliki siswa. ${ }^{3}$

Pendidikan inklusi menunjukkan perkembangan yang cukup signifikan di Indonesia, baik dari jenjang taman Kanak-kanak sampai dengan pendidikan lanjutan. SD Qaryah Thayyibah merupakan salah satu sekolah inklusi di daerah Purwokerto. Sudah tentu sekolah tersebut tidak menempatkan anak berkebutuhan khusus secara marginal, karena semua anak menyatu dan menjadi bagian dari setiap kegiatan belajar mengajar. Terdapat berbagai jenis kategori anak berkebutuhan khusus di sekolah tersebut, salah satunya adalah anak disabilitas intelektual.

Hal yang menarik dari SD Qaryah Thayyibah adalah sekolah ini merupakan salah satu lembaga pendidikan inlkusif yang berbasis Islami. Selain memberikan pelayanan pendidikan juga memberikan layanan terapi bagi siswa-siswa yang tergolong anak berkebutuhan khusus mengajarkan Bahasa Arab sebagai mata pelajaran yang berdiri

1 Dedy Kustawan dan Yuni Meimulyani, Mengenal Pendidikan Khusus dan Pendidikan Layanan Khusus Serta Implementasinya (Jakarta: Luximo Metro Media, 2013), 34.

2 Syaiful Bahri Djamarah dan Aswan Zain, Strategi Belajar Mengajar (Jakarta: Rineka Cipta, 2010),5.

${ }^{3}$ Sunhaji, Strategi Pembelajaran (Yogyakarta: Grafindo Litera Media, 2009), 37. 
sendiri, akan tetapi khusus mata pelajaran Pendidikan Agama Islam dan Bahasa Arab dijadwalkan pada hari jumat secara serempak mulai dari jenjang kelas I hingga kelas VI. Tujuan pembelajaran Bahasa Arab selain agar siswa menguasai bahasa itu sendiri diharapkan juga bahasa Arab dapat mengantarkan peserta didik dalam mencintai bahasa Arab sebagai wujud cinta Al Qur'an, yang berbahasa Arab. Di samping itu, pembelajaran Bahasa Arab diharapkan dapat mendorong peserta didik untuk mencintai Bahasa Arab sehingga anak berminat untuk berfikir dan belajar, sesuai dengan salah satu tujuan pendidikan di SD Qaryah Thayyibah.

Khusus untuk pembelajaran bahasa Arab, memang tidaklah mudah mengajarkan dan mengaplikasikan konsep-konsep materi pada ABK. Dalam kegiatan pembelajaran, termasuk pembelajaran bahasa Arab antara siswa yang berkebutuhan khusus dan siswa yang normal tidak dibedakan. Padahal permasalahan dalam proses pembelajaran sering kali terjadi karena keragaman kondisi siswa yang ada dalam satu kelas, tingkat pemahaman siswa yang bervariasi, maupun metode dan strategi pembelajaran yang kurang tepat. Terlebih berdasarkan fenomena yang peneliti temui di kelas III SD Qaryah Thayyibah, beberapa siswa yang tergolong penyandang disabilitas inetelektual yang bervariasi menurut kategori atau klasifikasinya. Sehingga hal tersebut menuntut pihak sekolah termasuk guru untuk melakukan modifikasi atau penyesuaian dengan adanya strategi yang berbeda dalam penyampaian materi baik secara metodelogi maupun kompetensi guru. Dengan harapan seluruh siswa baik non disabilitas maupun siswa disabilitas intelektual dapat menerima informasi dan mendorong kemampuan secara optimal. Meskipun, berdasarkan penuturan Kepala sekolah SD Qaryah Thayyibah, kemampuan atau hasil belajar siswa penyandang disabilitas intelektual memiliki standart tersendiri yang berbeda dengan siswa pada umumnya.

\section{METODE PENELITIAN}

Jenis penelitian ini merupakan penelitian lapangan (field research) dimana proses pengambilan data dilakukan di lapangan. Pada penelitian ini, pendekatan yang digunakan yaitu pendekatan penelitian kualitatif jenis analisis deskriptif. Karena data yang peneliti kumpulkan lebih banyak bersifat keterangan-keterangan atau pemaparan dari suatu peristiwa yang diteliti. Dengan pendekatan ini peneliti terjun langsung ke lapangan (lokasi penelitian) yakni SD Qaryah Thayyibah Purwokerto untuk mengamati tingkah, perilaku dan kondisi anak disabilitass intelektual yang ada di kelas III SD Qaryah Thayyibah.

Menurut Nana Syaodih penelitian kualitatif adalah suatu penelitian yang ditunjukan untuk mendeskripsikan dan menganalisis fenomena, peristiwa, aktifitas 
sosial, sikap, kepercayaan, persepsi, pemikiran orang secara individu maupun kelompok. ${ }^{4}$ Penelitian ini bersifat deskriptif kualitatif yaitu, penelitian yang dimaksudkan untuk mengumpulkan informasi atau data mengenai status gejala yang ada, yaitu keadaan gejala menurut apa adanya pada saat penelitian dilakukan. ${ }^{5}$ Subjek penelitian yang dipilih adalah guru kelas, guru pendamping, dan wali murid SD Qaryah Thayyibah Purwokerto. Adapun teknik pengumpulan data yang digunakan adalah observasi, wawancara, dan dokumentasi.

\section{PEMBAHASAN}

\section{A. ABK di kelas III SD Qaryah Thayyibah Purwokerto}

Perkembangan sekolah inklusi di daerah Purwokerto belum terlalu pesat, meskipun sudah ada peraturan yang mengatur bahwa sekolah wajib mengadakan kelas inklusi. SD Qaryah Thayyibah merupakan sekolah inklusi yang tergolong masih baru, hal tersebut disampaikan oleh Ust. Cecep selaku Kepala SD QiTa.

"SD QiTa sendiri ini tergolong sekolah baru mbak. Kita berdiri sejak tahun 2014. Kami juga belum mencetak lulusan, insyaAllah tahun ini baru mau meluluskan."6

Ada berbagai jenis anak disabilitas yang bersekolah di SD QiTa., namun sebagian besar rata-rata ABK yang bersekolah di SD QiTa adalah anak-anak disabilitass intelektual. Khusus untuk kelas III atau kelas Ali bin Abi Thalib yang terdiri dari 23 siswa, ada 7 siswa putri dan 16 siswa putra. 6 dari 23 siswanya adalah siswa ABK dan semuanya masuk kategori disabilitas intelektual. Berikut adalah data tabel anak disabilitas intelektual di kelas III.

\begin{tabular}{|l|l|l|}
\hline No. & Nama siswa & Jenis ABK \\
\hline 1. & Aulia R. Mahardika & Autisme \\
\hline 2. & Fatihatul A. Al Mughits & Cerebral Palsy \\
\hline 3. & Fathurrahman Hakim & Autisme \\
\hline 4. & Haidar Gazi Prasetyo & Autisme \& APHD \\
\hline 5. & Muhammad Fahrul Qayum & Autisme \\
\hline 6. & Rayen Mediansyah Syahreza & Down Syndrome \\
\hline
\end{tabular}

Hal tersebut serupa dengan pemaparan wali kelas III.

"Jumlah total ada 23 siswa, 7 putri dan 16 putra. 6 diantaranya ABK.

${ }^{4}$ Nana Syaodih Sukmadinata, Metode Penelitian Pendidikan (Bandung: PT. Remaja Rosdakarya, 2011), 60 .

5 Sugiono, Metode Penelitian Pendidikan Pendekatan Kualitatif, Kuantitatif dan R\&D, (Bandung: Alfabeta, 2013), 6.

${ }^{6}$ Wawancara dengan Cecep Supratno, S.Pi., Selaku Kepala SD Qaryah Thayyibah Purwokerto, pada tanggal 23 Februari 2020 pukul 11.00 WIB- selesai. 
Dan bisa dibilang semuanya itu tergolong disabilitas intelektual yah, walaupun dengan beberapa kategori. Di kelas 3 itu ada Fatih, dia anak Cerebral Palsy, Fathur, Dika, Haidar, Qayum, mereka termasuk kategori Autisme dan Rayen down syndrome."7

Anak disabilitas intelektual adalah anak yang secara signifikan memilliki kecerdasan dibawah rata-rata anak pada umumnya dengan disertai hambatan dalam penyesuaian diri dengan lingkungan sekitarnya. Mereka memiliki keterlambatan dalam segala bidang yang bersifat permanen. Rentang memori mereka pendek terutama berhubungan dengan akademik, kurang dapat berfikir abstrak dan pelik. ${ }^{8}$

Selain itu berdasarkan hasil data yang ada, 6 anak yang tergolong disabilitas intelektual itu termasuk kategori disabilitas intelektual Imbecil atau kategori sedang. Karena mereka mengalami kesulitan berbicara, dan kemampuan bahasa mereka juga terbatas, namun masih memungkinkan mendapatkan pelatihan. Akan tetapi taraf kemampuan mereka tidak sampai ke kemampuan membaca, berhitung dan berpikir hal-hal yang abstrak. Mereka lebih diarahkan untuk belajar mandiri, dan mampu beradaptasi dengan lingkungan. Hal tersebut sesuai dengan apa yang dikemukakan oleh Patton, bahwa anak Imbecil (sedang) tidak bisa seperti anak debil (ringan), kemampuan mereka hanya sebatas mendapat pelatihan mengurus diri sendiri, tanpa memungkinkan belajar seperti anak debil. ${ }^{9}$ Berdasarkan tinggi rendahnya kecerdasan intelegensi yang diukur dengan menggunakan tes Stanford Binet dan skala Wescheler (WISC), disabilitas intelektual digolongkan menjadi empat golongan:

1) Kategori Ringan (Moron atau Debil)

Pada kategori ringan, memiliki IQ 50-55 sampai 70. Berdasarkan tes Binet kemampuan IQ-nya menunjukkan angka 52-68, sedangkan dengan tes WISC, kemampuan IQ-nya55- 69.

2) Kategori Sedang (Imbesil)

Biasanya, pada kategori ini memiliki IQ 35-40 sampai 50-55. Menurut hasil tes Binet IQnya 36-51, sedangkan tes WISC 40-54.

3) Kategori Berat (Severe)

\footnotetext{
${ }^{7}$ Wawancara dengan Fitia Fatikka Rachman, S.Si., Selaku Wali kelas III SD Qaryah Thayyibah Purwokerto, pada tanggal 24 Maret 2020 pukul 09.00 WIB- selesai.

8 Nunung Apriyanto, Seluk Beluk Tunagrahita \& Strategi Pembelajarannya, (Yogyakarta : Javalitera, 2012), 21.

${ }_{9}^{9}$ Mohammad Efendi, Pengantar Psikopedagogik ..., 91.
} 
Kategori ini memiliki IQ 20-25 sampai 35-45. Menurut hasil tes Binet IQnya 20-32, sedangkan menurut tes WISC, IQ-nya 25-39.

4) Kategori Sangat Berat (Profound)

Pada kategori ini, penderita memiliki IQ yang sangat rendah. Menurut hasil skala binet IQ penderita dibawah 19, sedangkan menurut tes WISC IQ-nya dibawah $24 .{ }^{10}$

\section{B. Pembelajaran Bahasa Arab bagi ABK di kelas III SD Qaryah Thayyibah Purwokerto}

Guru di kelas tersebut menggunakan beragam strategi dalam pembelajaran bahasa Arab. Sebagaimana hasil wawancara dengan ustadzah Eri beliau menyatakan;

"Untuk pembelajaran bahasa Arab saya biasanya menggunakan metode ceramah dan diskusi dan terkadang diselingi dengan permainan. Saya sering menggunakan media gambar terus nanti ada permainannya juga, karena materi kelas 3 kan kebanyakan masih seputar kosakata. Kalau strateginya saya sering menggunakan strategi CTL, jadi apa yang dipelajari itu dikaitkan dengan kehidupan biar anak tuh lebih paham untuk apa mereka mempelajari materi tersebut. Selain itu saya juga terapkan strategi kooperatif, jadi anak itu lebih efektif kalau belajar berkelompok. Karena kebetulan kelas saya kan anaknya banyak, jadi akan lebih kondusif kalau dibuat kelompok. Tapi bagi ABK sendiri, belum ada strategi ataupun metode khusus mbak. Yang penting anak-anak hebat itu bisa mengikuti pembelajarannya saja. Jadi dalam bahasa Arab sendiri mereka cukup mengenal saja. Misalkan materi (kosakata/mufrodat benda-benda di dalam kelas), ya mereka cukup dikenalkan saja. Karena anak-anak hebat itu kan istimewa ya mbak, mereka tidak bisa disamakan dengan anak lain. Sekalipun mereka ditempatkan dalam satu kelas yang sama, mereka ya cukup mengikuti dan mengenal tanpa ada keharusan untuk memahaminya. Lagi pula kalau ABK itu kan belajar khususnya di ruang terapi, jadi kalau di kelas ya cukup mengikuti, tanpa menggangu anak-anak yang lain saja itu sudah cukup. Dan kami juga belum memiliki program khusus untuk tiap mata pelajaran yang diberikan pada ABK. Paling kami memberikan tugas lain disaat pembelajaran. Misalkan, saat saya mengajarkan kosakata tentang benda-benda di kelas, ya mereka paling saya beri gambar dan mereka suruh mewarnai. Atau kadang juga dengan melatih kemampuan menulis arab mereka, saya buatkan titik-titik membentuk huruf-huruf hijaiyah,

\footnotetext{
${ }^{10}$ Aqila Smart, Anak Cacat Bukan Kiamat ... , 49-51.
} 
lalu mereka nanti disuruh menulis mengikuti pola titik yang sudah dibuatkan. Begitu si paling mbak."11

Contextual Teaching and Learning (CTL) adalah suatu strategi pembelajaran yang menekankan kepada proses keterlibatan siswa secara penuh untuk menemukan materi yang dipelajari dan menghubungkannya dengan situasi kehidupan nyata sehingga mendorong siswa untuk dapat menerapkannya dalam kehidupan mereka. ${ }^{12}$

Bahasa arab di kelas tersebut hanya dilakukan sebatas pengenalan bagi siswa anak berkebutuhan khusus. Hal tersebut disesuaikan dengan kemampuan mereka sebagaimana karakteristik anak berkebutuhan khusus yaitu;

1) Memiliki pengetahuan umum yang sangat terbatas.

2) Sangat sulit memahami ide-ide yang abstrak.

3) Keterampilan membaca dan menulis sangat rendah.

4) Strategi dalam upaya mengembangkan kemampuan membaca dan belajar sangat rendah.

5) Sangat sulit mentransfer ide tertentu ke dalam situasi nyata.

6) Keterampilan motorik berkembang sangat lambat.

7) Keterampilan interpersonal sangat tidak matang. ${ }^{13}$

Sebagaimana hasil wawancara dengan salah satu guru di kelas tersebut; "Usaha kita mengenalkan. Karena tahap memahami masih belum memungkinkan. Paling untuk mensiasati mengenalkan materi, kita mencari kegiatan yang sesuai dengan kemampuan anak-anak hebat. Kalau buku, tidak ada yang khusus juga yah. Jadi B. Arab ini kan termasuk mata pelajaran muatan lokal, jadi biasanya gurunya sendiri yang membuat materi dan juga kisi-kisinya lalu diperbanyak dan dibagikan kepada semua siswa. Kalau anak hebat indikatornya semua Mengenalkan. Penilaian mereka itu berdasarkan partisipasi, (mengikuti pembelajaran di dalam kelas, mampu duduk tertib rapi) sudah dianggap mengikuti pembelajaran. Dan rapornya pun berbeda mbak, ABK itu rapornya bukan nilai angka tapi penilaian huruf."14

${ }^{11}$ Wawancara dengan Eri Yulia Pratiwi, S.Pd., Selaku Guru mata pelajaran Bahasa Arab kelas III SD Qaryah Thayyibah Purwokerto, pada tanggal 23 Maret 2020 pukul 10.00 WIB- selesai

12 Wina Sanjaya, Strategi Pembelajaran ..., 25.

${ }^{13}$ I Nyoman Surna dan Olga D. Pandairot, Psikologi Pendidikan 1 (Jakarta: Erlangga, 2014), 220.

${ }^{14}$ Wawancara dengan Eri Yulia Pratiwi, S.Pd., Selaku Guru mata pelajaran Bahasa Arab... 
Proses pengenalan bahasa Arab oleh guru tersebut sesuai dengan prinsip pendidikan bagi Anak Berkebutuhan Khusus yaitu Prinsip kasih sayang dan prinsip keperagaan. ${ }^{15}$

\section{KESIMPULAN}

Berdasarkan pemaparan hasil penelitian dan pembahasan yang telah dilakukan dapat disimpulkan bahwa Anak Berkebutuhan Khusus (ABK) yang berada di kelas III SD Qaryah Thayyibah Purwokerto adalah ABK dengan klasifikasi disabilitas Intelektual. Pembelajaran Bahasa Arab yang dilakukan oleh guru adalah pengenalan bahasa Arab yang didasarkan dengan kemampuan ABK masing-masing.

\section{DAFTAR PUSTAKA}

Apriyanto , Nunung, Seluk Beluk Tunagrahita \& Strategi Pembelajarannya, Yogyakarta: Javalitera, 2012

Aswan, Zain dan Syaiful Bahri Djamarah, Strategi Belajar Mengajar, Jakarta: Rineka Cipta, 2010

Efendi, Mohammad, Pengantar Psikopedagogik Anak Berkelainan, Jakarta: Remaja Rosdakarya, 2006

Meimulyani, Yuni dan Dedy Kustawan, Mengenal Pendidikan Khusus dan Pendidikan Layanan Khusus Serta Implementasinya, Jakarta: Luximo Metro Media, 2013

Pandairot, Olga D., dan I Nyoman Surna, Psikologi Pendidikan 1, Jakarta: Erlangga, 2014

Smart, Aqila, Anak Cacat Bukan Kiamat-Metode Pembelajaran dan Terapi untuk Anak Berkebutuhan Khusus. Yogyakarta: Katahati, 2010

Sugiono, Metode Penelitian Pendidikan Pendekatan Kualitatif, Kuantitatif dan R\&D, Bandung: Alfabeta, 2013

Sukmadinata, Nana Syaodih, Metode Penelitian Pendidikan, Bandung: PT. Remaja Rosdakarya, 2011

Sunhaji, Strategi Pembelajaran, Yogyakarta: Grafindo Litera Media, 2009

${ }^{15}$ Aqila Smart, Anak Cacat Bukan Kiamat ... , 49-51. 